\title{
Os advérbios já, mais e ainda nas orações negativas
}

\author{
Maria Angélica Furtado da Cunha \\ Nubiacira Fernandes de Oliveira \\ Universidade Federal do Rio de Janeiro
}

\section{Abstract}

This paper follows a functional approach which takes into account the real use of language as an instrument of communication. We are mainly interested in investigating the ways through which syntax, semantics and pragmatics interact. In order to do this, we study the behaviour of the adverbs $j a$, mais and ainda in negative sentences. First, we review the use of some elements which reinforce the very idea of negation. Secondly, we deal, specifically, with the adverbs, $j a$, mais and ainda as a reinforcement to the negative. Thirdly, we aim at verifying their behaviour from an argumentative perspective. Finally, we present our conclusions. 


\section{INTRODUÇÃO}

$\mathrm{E}$

ste trabalho segue uma linha de pesquisa de orientação funcionalista que leva em conta o uso real da língua enquanto instrumento de comunicação. Interessa-nos, em especial, observar o modo pelo qual sintaxe, semântica e pragmática interagem. Para tanto, examinamos o comportamento dos advérbios $j a ́$, mais e ainda em orações negativas.

Os dados examinados provêm de diferentes corpora que registram o português de Natal: História da Cidade do Natal, de Câmara Cascudo (CC), Revista Vivência (V) e matérias publicadas nos jornais Tribuna do Norte (TN), Diário de Natal (DN), O Poti (P) e Dois Pontos (DP).

Investigamos orações negativas que apresentam não antes do verbo, excluindo da análise orações com outras partículas de sentido negativo (sequer, jamais, nunca, por exemplo) por acreditarmos que essas partículas acrescentam outros significados à oração. Obtivemos um total de 91 negativas que apresentam os advérbios alvo deste estudo.

A primeira parte deste trabalho aborda o uso de elementos que servem de reforço à própria idéia de negação. Tratamos especificamente, na segunda seção, dos advérbios $j a ́$, mais e ainda como reforço nas negativas, enquanto, na terceira, buscamos verificar o seu funcionamento numa perspectiva argumentativa. A quarta seção reúne nossas conclusões.

\section{O REFORCO NAS NEGATIVAS}

Alguns gramáticos do português assinalam o uso, em orações negativas, de certos elementos cujo efeito é reforçar a negação. Em geral, os gramáticos associam esses elementos a termos negativos, como nada, nenhum, ninguém. Segundo Barreto (1954:73), 
“... o amontoar de negações para evitar dúvidas ou para maior reforço é coisa portuguesíssima. A nossa língua antiga empregava a negativa ainda quando antes do verbo já há um elemento negativo... O português com duas negações nega com mais energia." Said Ali (1964:198) afirma: "Para o povo, o acúmulo de negativas indica reforço... Diferentemente de nós (a gente de Letras), e de acordo com a linguagem vulgar, os escritores antigos, e ainda alguma vez os quinhentistas, empregavam sem restrições a negação dupla, e até tríplice, com efeito reforçativo."

A presença de outra forma negativa, além do não, dentro da mesma oração é também registrada por alguns lingüistas em diferentes línguas. Mattoso Câmara (1976:238) ressalta que "em princípio, o português não adotou o esquema, que se fixou por exemplo em francês, de uma segunda partícula depois do verbo para reforçar o intento negativo. Há, entretanto, uma construção com pronome indefinido negativo, como é o emprego de nada: Não quero nada. $\overline{\mathbf{E}}$ a rigor um objeto direto negativo, e; nesse sentido, alterna com a locução coisa nenhuma, mas o caráter de reforço negativo prepondera sobre essa função sintática." Payne (1985:224) afirma que há uma forte tendência para as partículas negativas serem enfatizadas e reforçadas, algumas vezes pela adição da própria partícula, como em latim nõn, mas mais freqüentemente pela adição de outra partícula em outra parte da sentença, como em francês ne... pas, formando um par de negativas associadas.

A título de exemplificação do reforço negativo, vejam-se as sequiências abaixo encontradas em nosso corpus:

(1) ... A consciência humana não poderá nunca ficar presa àqueles simples horizontes que a circundam. (V, p. 9)

(2) Não se pode negar, de nenhuma maneira, a importância que teve a utopia para a reflexão educativa. (V, p. 26)

(3) Não adianta, de nenhum modo, acumular conhecimentos sobre conhecimentos. (V, p. 26)

(4) Aristóteles não tem nenhuma teoria sobre a criação divina. (V, p. 108)

O reforço nas negativas pode ainda ser expresso por itens não necessariamente negativos em si mesmos. Silva Neto (1976:316) chama a atenção para o uso dos advérbios mais e já em orações 
negativas: "Com respeito ao advérbio mais, uso é vulgar entre os escritores brasileiros dar-lhe às vezes o valor significativo do advérbio já, em certas frases negativas, onde intervém como elemento de reforço. Assim que se diz: $O$ doente já não fala mais, não se move mais - em vez de: O doente já não fala, já não se move." Com enfoque semelhante, Coutinho (1978:340) comenta que, embora Júlio Moreira (1913) tenha atribuído ao dialeto brasileiro o uso de mais, nas frases negativas, em lugar do já, há exemplos que atestam que tal uso era corrente entre antigos escritores portugueses .

Nesta seção pretendemos mostrar, com base no registro de diversos estudiosos, que é comum, nas orações negativas, a ocorrência de itens, de sentido negativo ou não, cujo efeito é reforçar a própria idéia de negação. Esse fato levou-nos a observar as circunstâncias que explicam o uso de alguns advérbios na negativa. Restringimos nossa investigação a $j a ́$, mais e ainda, classificados pela gramática como advérbios de tempo.

\section{JA, MAIS E AINDA COMO REFORÇO NAS NEGATIVAS}

Nas gramáticas do português, o advérbio é definido como a palavra que denota uma circunstância de lugar, tempo, modo, grau ou intensidade, negação, dúvida, etc. e que serve como determinante ao verbo, ao adjetivo ou a outro advérbio (cf. Said Ali (1961), entre outros). Cunha \& Cintra (1985) mencionam ainda que $o$ advérbio pode modificar também todo 0 enunciado.

Segundo essa definição, os itens $j a ́$, mais e ainda são classificados como advérbios temporais, já que denotam uma circunstância de tempo e modificam, de algum modo, a idéia expressa pelo verbo da oração em que ocorrem.

Os advérbios temporais já e ainda não têm, em si mesmos, um valor positivo ou negativo, tanto podem ocorrer em orações afirmativas quanto em orações negativas. Contudo, esses advérbios manifestam uma variação de sentido caso ocorram em uma ou outra modalidade de oração. Na afirmativa, já é usado para marcar a chegada a um ponto esperado ou o término de um processo, enquanto ainda assinala a continuidade de um estado ou pro-

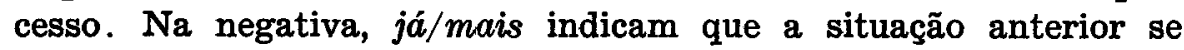
alterou, ao passo que ainda marca a manutenção da situação anterior. Deste modo, a negação do já é ainda não e a negação do ainda é já não (cf. Costa (1986)). Vejamos alguns exemplos: 
(5) Os contratos já foram firmados com a TV Tropical, que vai fazer a transmissão do bingo. (TN, 01/06/90).

(6) Os jogadores, mais do que nunca, sabem que ainda estão na frente e podem manter a esperança de conquistar o terceiro turno. (TN, 06/06/90).

Em (5) o emprego de já indica que a ação verbal foi concluída e chegou-se ao ponto esperado (a firmação dos contratos, confirmada na oração seguinte) ; em (6) o uso de ainda assinala que a situação anterior se mantém (os jogadores continuam a ocupar a primeira posição) .

(7) Já não desperta a atenção de agora esse aspecto do fidelismo lusitano. (CC, p. 45) .

(8) Adversário ainda não marcou gols no campeonato. (TN, 28/10/90).

$\mathrm{Na}$ negativa em (7), já é usado para marcar a alteração da situação anterior - certo aspecto do fidelismo lusitano deixou de despertar a atenção como acontecia antes; em (8), o emprego de ainda, na manchete da matéria, ressalta que o adversário continua sem marcar gols, ou seja, que a situação anterior permanece inalterada.

Com relação à ocorrência de mais com valor temporal, vale notar que ela só se dá em orações negativas, como:

(9) $O$ ponteiro direito Nilton não pertence mais do Alecrim.

Nessa oração, o uso de mais corresponde ao de já: indica que houve mudança na situação anterior - Nilton foi excluído da equipe alecrinense.

Compare o uso de mais em (9) com o seu uso em (10) e (11):

(10) Ele, que foi um dos dirigentes que mais lutou pela recuperação do futebol do estado, agora não está nem um pouco preocupado. (TN, 29/04/90).

(11) uma festa típica de trabalhador, onde a confraternização vale mais que a competição (TN, 29/04/90).

$\mathrm{Na}$ oração afirmativa sublinhada em (10), mais intensifica o verbo; em (11), estabelece uma comparação entre confraternização e competição. Em ambos os casos, o advérbio mais não tem qualquer conotação temporal. 
Nossos dados confirmam a observação feita por alguns gramáticos (cf. Seção 1) de que, com valor temporal, mais alterna com $j a ́$ em orações negativas. Comprovam, também, a preferência pelo uso de mais, em substituição a já, nessas orações. No texto histórico, registramos apenas uma ocorrência de já contra duas de mais; no texto científico ocorre um $j a ́$ para três mais; no texto jornalístico encontramos vinte e seis ocorrências de mais e nove de já. interessante notar que, no texto jornalístico, há duas orações negativas em que já e mais co-ocorrem, como em:

(12) Também falam que a Ministra Zélia já não tem mais aquela corda toda do Palácio do Planalto. (TN, 08/05/91) .

Esses números indicam que a predominância dos advérbios temporais na negativa se dá no registro menos formal que, em nosso corpus, corresponde ao texto jornalístico. Observe-se o quadro abaixo, que apresenta a distribuição desses advérbios por texto:

\begin{tabular}{|c|c|c|c|c|}
\hline & JA & MAIS & AINDA & TOTAL \\
\hline $\mathbf{C C} \ldots \ldots \ldots \ldots \ldots \ldots \ldots$ & 01 & 02 & 01 & 04 \\
\hline $\mathbf{v}$. & 01 & $\mathbf{0 3}$ & 01 & 05 \\
\hline $\mathbf{J} \ldots \ldots \ldots \ldots \ldots \ldots \ldots \ldots$ & 09 & 26 & 47 & 82 \\
\hline
\end{tabular}

Em seu trabalho sobre a posição dos advérbios, Ilari (1990:79) considera duas dimensões para a classificação desses itens: a primeira é a dos segmentos sintáticos a que o advérbio se aplica; a segunda é a das funções que ele desempenha. Posição e função estão intimamente relacionadas: a posição que o advérbio ocupa na oração se define funcionalmente, pois depende do constituinte que ele toma como escopo. ${ }^{1}$ Essa posição está relacionada a várias propriedades de natureza sintática e semântica. Há, em geral, uma posição preferencial para cada paradigma de advérbio, o que não exclui a possibilidade de que os advérbios se desloquem para outras posições. Em suma, "a posição depende, em cada caso, da função que o advérbio exerce ao mesmo tempo que contribui para identificar essa função." (p. 135) .

Com função temporal, a posição não marcada de já, mais e ainda é a fronteira de parte do constituinte SV, mais precisamente, NAO + V (verbo), com oitenta e oito dados em nosso corpus. Uma vez que o operador não incide sobre $\mathrm{V}, j a ́$, mais e ainda agem sobre o conjunto de conteúdos expressos por $\mathrm{NAOO}+\mathrm{V}$. 
Esses advérbios "quebram" o constituinte SV porque agem apenas sobre NÃO + V, ficando os complementos de V fora do seu escopo, como o circunstancial a Natal em (15) e o objeto indireto aos advogados em (16) abaixo. $\overline{\mathrm{E}}$ por incidir sobre NÃO $+\mathrm{V}$, acrescentando-lhe uma circunstância de tempo, que já, mais e ainda ocorrem nos limites de NÃO + V. Assim, podem aparecer:

(a) imediatamente antes de NÃO $+\mathrm{V}: 50$ ocorrências.

(13) Ainda não temos a premiação oficial. Mas vai ser uma tentação para os jogadores. (TN, 01/06/90).

(14) As forças políticas já não encaminham qualquer solução. (DN, 08/05/91).

(b) imediatamente após NÃO + V: 38 ocorrências.

(15) A outra informação que chegou ontem à noite na Federação, ; que a Comissão da CBF, comandada por José Bonnetti, não vem mais a Natal esta semana. (TN, $09 / 05 / 91$ ).

(16) Para provar que era filho de Roberto Carlos, Rafael, seu filho mais velho, está às voltas com a justiça porque não pagou ainda aos advogados que questionaram a causa e exigem pagamento aos honorários. (DN, 07/05/91).

Em nosso corpus, já ocorre sempre à esquerda de NÃO $+\mathrm{V}$, mais à direita e ainda pode ocorrer tanto à direita quanto à esquerda. Embora possam co-ocorrer na oração (cf. (12), já e mais têm posições fixas e excludentes. Na negativa, por serem semanticamente equivalentes, $j a ́$ e mais são intercambiáveis; sintaticamente, porém, cada um deles ocorre em um ambiente específico, à esquerda e à direita de $\mathrm{NÃO}+\mathrm{V}$, respectivamente.

Registramos, ainda, três ocorrências de mais entre NÃO $+\mathrm{V}$ :

(17) ... não mais voltaram os sucessores do velho Senado da Câmara ao governo do Rio Grande do Norte; tendo apenas os votos da Cidade do Natal. (CC, p. 64).

A paucidade de ocorrências de mais nessa posição marcada não nos permite uma explicação definitiva: mesmo estando entre NAOO $+\mathrm{V}$, mais continua a afetar o conteúdo representado por 
essa sequiência. Nossa hipótese é a de que o deslocamento de mais para o interior de NÃO $+\mathrm{V}$ deve-se a razões de ordem estilística. Note-se, ainda, que duas das três ocorrências de mais nessa posição representam orações com a ordenação marcada Verbo - Sujeito, como em (17) acima. A outra tem sujeito anafórico:

(18) Pela ordem, Vamberto e Riva, foram os primeiros a chegarem a um acordo, e não mais retornarão para o Alvinegro. (TN, 20/10/90).

Consideramos que os advérbios temporais já, mais e ainda, incidindo sobre parte do conteúdo do enunciado negativo, ou seja, a sequiência $\mathrm{NÃO}+\mathrm{V}$, constituem um reforço à própria negação. Uma vez que a negativa informa que a ação (ou idéia) expressa pelo verbo não se dá, já, mais e ainda reforçam o não-acontecimento dessa ação (ou idéia), situando-o no tempo. Já não e não mais indicam que a situação anterior se modificou; portanto, apontam para o presente em relação a uma situação passada. Ainda não indica a manutenção da situação anterior, apontando para o futuro em relação a uma situação presente.

\section{A NATUREZA ARGUMENTATIVA DE JĀ, MAIS E AINDA NAS NEGATIVAS}

Alguns autores questionam a definição tradicional de advérbio argumentando que certos itens, classificados como advérbios pelas gramáticas, não expressam circunstância, não dizem respeito ao processo verbal nem são intensificadores. Assim é que Bonfim (1988:7-10) assinala que os chamados advérbios de negação, afirmação e dúvida expressam uma opinião do locutor ou sua dúvida sobre o enunciado ou parte dele. Nesse sentido, esses "advérbios" têm aspecto subjetivo pois revelam a interferência do emissor sobre a mensagem enunciada. No caso dos advérbios de dúvida (provavelmente, talvez, etc.), por exemplo, Bonfim defende que a falta de certeza é do sujeito da enunciação e não do processo verbal. Souza e Silva \& Koch (1983:19-21) compartilham esse ponto de vista ao afirmarem que o advérbio pode indicar atitudes do falante, como em:

(19) Felizmente, não houve vítimas no desastre.

(20) Provavelmente, o comício não se realizará. 
Em (19) e (20), felizmente e provavelmente não fazem parte do conteúdo proporcional; no primeiro exemplo felizmente "exprime os sentimentos do falante perante o fato veiculado pela proposição", enquanto no segundo, provavelmente "revela o seu grau de engajamento relativamente ao enunciado que produz." (p. 20). Em ambos os casos, esses advérbios funcionam como modalizadores ou modificadores atitudinais.

Para Ilari et alii (1990:122), "os modalizadores são advérbios que se aplicam à sentença como um todo (podendo haver caso em que há incidência focal sobre um constituinte), não se incluem no conteúdo proposicional por ela expresso, mas operam sobre ele ou sobre a asserção de que é objeto." Citam, como paradigmas desses advérbios, felizmente, talvez, etc. (Cf. Castilho \& Castilho, 1992).

Vimos que os advérbios já, mais e ainda, nas negativas, funcionam como elemento de reforço. O que pretendemos demonstrar, agora, é que ao lado de sua função de marcador da categoria de tempo, nas orações negativas esses advérbios funcionam como marcadores da atitude do falante em relação ao enunciado. nesse sentido que consideramos que esses itens possuem um caráter argumentativo. O que está em jogo nessa diferença de funcionamento é o ponto de vista analítico que se adota. Enquanto uma abordagem se limita a descrever o uso desses elementos no nível do enunciado, como marcadores da categoria de tempo e/ou reforço da negativa, a outra vai além, observando o seu uso no nível da enunciação, como indicadores da atitude do falante. Essas duas abordagens não são excludentes mas se sobrepõem. Vejamos alguns exemplos:

(21) E, em breve, a Teoria Sociológica Geral será uma realidade, uma vez que o sectarismo interno está sendo minimizado... já nẫo se enfatiza tanto nem a sociologia durkheimiana, nem a marxista, nem a weberiana ou coisa que o valha, trata-se de libertar-se da filosofia e de traçar seus próprios caminhos. (V, p. 66).

A oração negativa em (21) tem como pressuposto o fato de que os diversos tipos de sociologia mencionados (a durkheimiana, a marxista e a weberiana) eram enfatizados. Esse é o pressuposto associado à própria negativa, independente do uso do advérbio $j a ́$ : a eliminação desse advérbio não altera essa pressuposição. Por um lado, a negativa estabelece que os tipos de sociologia referidos não 
são enfatizados. A presença do advérbio já nos informa que houve uma mudança com respeito a uma situação anterior - da ênfase para a não-ênfase, do sim para o não. Ao empregar o advérbio já, o locutor, ao mesmo tempo em que reforça a não-continuidade da ação verbal, expressa sua opinião sobre o enunciado, mais especificamente, seu sentimento de satisfação face à mudança de situação, que permitirá que a sociologia constitua uma teoria própria. $\overline{\mathbf{E}}$ nesse sentido que $j a ́$ pode ser considerado um modalizador.

O exemplo de já em (22) foi constatado no texto jornalístico:

(22) Quem tem olhos e quer ver pode perceber que o Governo caminha para um impasse perigoso. E já há quem diga que o segundo semestre trará alguns momentos de dificuldades; dificuldades políticas, econômicas e sociais. E não é apenas a economia que está desarticulada; as forças políticas já não encaminham qualquer solução. (DN, 08/05/91).

A pressuposição da oração destacada em (22) é a de que as forças políticas encaminhavam soluções para as dificuldades do país. Essa pressuposição é desfeita pelo uso do não. $\mathrm{O}$ advérbio já, agindo sobre a negativa, assinala uma mudança consumada da situação anterior, do sim para o não. Funcionando como modalizador do enunciado, já revela também a opinião ou a postura crítica do locutor em relação a essa mudança.

Observemos, agora, o uso de mais, com a mesma função argumentativa de já, no texto jornalístico.

(23) Após a corrida, no circuito de Monte Carlo, Senna não poupou críticas ao desempenho do motor Honda. "Não tenho mais a vantagem que tínhamos no passado", reclamou. (TN, 29/06/90)

A negativa de Senna faz parte do pressuposto de que ele tinha vantagem anteriormente. Do uso de mais em (23) depreende-se a mudança ocorrida, que é enfatizada pela oração relativa (que tínhamos no passado) presente no próprio enunciado. Nesse exemplo, mais marca a atitude de insatisfação do locutor (Senna) 
com respeito à situação atual. Esse sentimento de insatisfação é reconhecido pelo redator da matéria, que descreve a fala de Senna como uma reclamação.

Ainda um outro exemplo:

(24) $O$ novo empenho dos jogadores do $A B C$ agora não é mais para ganhar do próximo adversário, porém o de "cair em campo" para vender mais ingressos referentes ao amistoso contra o Auto Esporte de João Pessoa. (TN, 24/06/90).

O pressuposto da negativa em (24) é o de que o empenho dos jogadores do $\mathrm{ABC}$ era ganhar do adversário. $\mathrm{O}$ advérbio mais, associado à negativa, informa o leitor de que houve mudança no comportamento dos jogadores: eles não estão interessados em ganhar a partida, e sim em aumentar a renda do jogo. O contraste entre a situação anterior e a atual é confirmado pela presença, na oração sublinhada, do adjetivo novo e do advérbio agora. Além disso, a própria manchete dessa matéria se refere à situação atual: Jogadores do ABC correm atrás do "bicho". Como modalizador, mais expressa uma postura crítica do enunciador face a essa mudança.

Vejamos, a seguir, o comportamento do advérbio ainda nas negativas. O exemplo abaixo foi retirado do Jormal Tribuna do Norte:

(25) As eleições no clube alvirrubro ainda não têm data programada, mas acontecerão até o final de dezembro. (TN, 28/10/90).

O texto anterior a esse exemplo aborda a necessidade de composição de uma nova diretoria do Potiguar, até então dirigido por uma junta governativa, para viabilizar a realização do próximo certame. Dada essa necessidade, a pressuposição em (25) é a de que as eleições já têm data marcada. A negativa desfaz essa suposição - não se sabe a data certa das eleições. O uso de ainda na oração negativa revela a crença do locutor, compartilhada pelo ouvinte, na veracidade da realização do processo eleitoral do Potiguar, o que é reforçado pela oração imediatamente seguinte: 
mas acontecerão até o final de dezembro. Assim, ainda assegura o ouvinte de que o evento se realizará, projetando a ação para o futuro e implicando uma mudança em relação à situação presente.

A negativa em (26) abre a coluna Esportes, da Tribuna do Norte, sob o título Mala Fechada.

(26) Até agora o América ainda não decidiu abrir a "mala" para estimular o Baraúnas no jogo de amanhã com o ABC. (TN, 15/05/90).

Uma vez que o jogo aconteceria no dia seguinte à publicação da matéria, o leitor assíduo de notícias esportivas esperaria que o América já tivesse decidido "abrir a mala". Essa é a pressuposição em (26). A negativa contradiz essa expectativa. O emprego de ainda, junto com a negativa, expressa a crença do locutor na mudança da situação atual - da "mala fechada" para a "mala aberta", do não (presente) para o sim (futuro). A expectativa veiculada pelo ainda é confirmada pela expressão temporal até agora presente no início da oração. Essa expressão marca o limite de manutenção da situação presente ao mesmo tempo que reforça a mudança futura assinalada pelo ainda.

Cabe observar que, em seu trabalho sobre operadores de argumentação, Vogt (1977) ressalta o caráter argumentativo de ainda, classificando-o como marcador de excesso. Para ele, ainda "traz para o interior do enunciado a marca de uma apreciação do locutor." (p. 97).

O exame dos exemplos apresentados evidencia que, além de funcionarem como marcadores temporais da ação verbal, os advérbios $j a ́$, mais e ainda, empregados na negativa, desempenham um outro papel, que está diretamente relacionado ao conceito de argumentação. Como operadores argumentativos, esses advérbios não se incluem no conteúdo proposicional expresso pela sentença negativa mas operam sobre ele, indicando uma atitude do falante, que avalia o próprio conteúdo proposicional. São, assim, modalizadores. Nesse caso, o valor desses advérbios desloca-se do âmbito da proposição para a situação de enunciação, ou seja, para a crença ou expectativa do falante (Cf. Castilho \& Castilho, 1992-230-1).

Segundo nlari (1990), a posição preferencial dos advérbios modalizadores é periférica na oração - preferencialmente, a inicial e, em menor número, a final. Contudo, assinala que alguns desses 
advérbios, como realmente, por exemplo, "se aplicam não à sentença, mas a constituintes claramente delimitados da mesma." (p. 129-130). Esse é o caso dos advérbios que estamos analisando. Embora desempenhem o papel de modalizadores, $j a ́$, mais e ainda não incidem sobre toda a sentença, e sim sobre uma parte claramente delimitada do constituinte SV, ou seja, NAOO $+\mathrm{V}$, que tomam como escopo.

\section{CONCLUSOEAS}

Tradicionalmente, a classificação dos advérbios é feita com base no critério nocional. A função que um dado advérbio desempenha é genericamente chamada de modificação. Essa generalização tem obscurecido outras funções que os advérbios são chamados a desempenhar no uso efetivo da linguagem enquanto instrumento de comunicação. E que acontece com os advérbios aqui examinados, comumente classificados como advérbios temporais. Os dados analisados revelam que há razões para se questionar a validade da aplicação desse critério. que não leva em conta as circunstâncias da própria enunciação, ignorando o papel argumentativo particular de $j a ́$, mais e ainda nas negativas - o de expressar a opinião ou expectativa do enunciador sobre o enunciado ou parte dele.

Com relação a já, mais e ainda, usados em orações negativas, adotamos, neste trabalho, uma posição alternativa. Entendemos que esses advérbios possuem uma dupla natureza, conforme o nível de análise enfocado. No nível sintático-semântico, são advérbios de constituinte, incidindo sobre NÃO $+\mathrm{V}$; no nível discursivo/ pragmático, sua ação extrapola a própria sentença, indicando uma operação argumentativa. No primeiro caso, concordamos com Costa (1986:175-8) que essas formas são marcadores da categoria de tempo. No segundo caso, consideramos que esses itens estão ligados à própria enunciação, apresentando-se como modalizadores do predicado negativo. Revelam, assim, a interferência do emissor sobre a mensagem transmitida. Um estudo que se pretenda completo não pode deixar de considerar a interação entre fatos gramaticais e discursivos no funcionamento desses advérbios no uso real. 
Nosso objetivo, neste trabalho, foi o de fornecer subsídios para uma discussão sobre a classificação tradicional dos advérbios, tomando como ponto de partida $j a ́$, mais e ainda. Dada a limitação do nosso corpus e a especificidade das fontes dos dados, consideramos prematuro propor uma generalização a respeito das estratégias que o locutor mobiliza no processo enunciativo. Toda contribuição no sentido de refinar essa análise será bem-vinda.

\section{NOTAS}

1 o escopo do advérbio é o conjunto de conteúdos por ele afetados. 2 1

A noção de pressuposição que adotamos segue Ducrot $(1981,1987)$.

\section{REFERENCIAS BIBLIOGRÄFICAS}

BARRETO, Mário. Factos da lingua portuguesa. 2. ed. Rio de Janeiro: Organizações Simóes, 1954.

BONFTM, Eneida. Advérbios. São Paulo: Atíca, 1988.

CAMARA Jr., J. M. História e estrutura da lingua portuguesa. Rio de Janeiro: Padrão, 1979, p. 56-69.

CAstilho, A. T, CASTILho, C. M. M. Advérbios modalizadores. In: ILARI, R. (Org.) . Gramática do português falado. Campinas: Editora da UNICAMP, 1992. v. 2: Niveis de análise lingústica, p. 213-260.

COSTA, Sônia B. Tempo e aspecto em já e ainda. In: Simpósio sobre diversidade linguistica no Brasil, 1, 1986, Salvador: Atas... Salvador, UFBa, 1986.

COUTINHO, Ismael de Lima. Gramática histórica. $7^{\text {* }}$ ed. Rio de Janeiro: Ao Livro Técnico S. A., 1978.

CUNHA, Celso, CINTRA, Lindley. Nova gramática do português contemporaneo. Rio de Janeiro: Editora Nova Fronteira S. A., [s.d.] .

DUCROT, O. Provar e dizer. São Paulo: Global Universitária, 1981.

- O dizer e o dito. São Paulo: Pontes, 1987.

ILARI, et al. Considerações sobre a posição dos advérbios. In: Castilho, A.T. (Org.). Gramática do português falado. Campinas: FAPESP/Editora da UNICAMP, 1990. v. 1: A ordem, p. 63-141.

MOREIRA, J. Estudos de lingua portuguesa. Lisboa: [s.n.], 1913. 
PAYNE, John R. Negation. In: SHOPEN, T. (Ed.). Language typology and syntactic description. Cambridge: Cambridge University Press, 1985. v. 1: Clause structure.

SAID ALI, M. Gramática secundária da lingua portuguesa. Brasília: Universidade de Brasília, 1964.

SILVA NETO, Serafim da. Gramatica normativa da lingua portuguesa. 184 ed. Rio de Janeiro: Livraria São José, 1976.

SOUZA E SILVA, M. C. P. de \& KOCH, I. V. Lingüística aplicada ao português: sintaxe. São Paulo, Cortez, 1983.

VOGT, Carlos. O intervalo semântico. São Paulo, Atica, 1977.

\section{Fonte dos dados}

CASCUDO, L. da C. História da cidade do Natal. Rio de Janeiro, Civilização Brasileira, $2^{a}$ edição, 1980.

Jornais Tribuna do Norte, Diário de Natal, O Poti e Dois Pontos, anos 1990 e 1991.

Revista Vivência, vol. II, n゚ 4, 1984. Editora Universitária, UFRN. 